\title{
HUBUNGAN BEBAN KERJA DENGAN BURNOUT PERAWAT
}

DI INSTALASI GAWAT DARURAT RSUD NGANJUK

\author{
Fitrah Handika Hutama ${ }^{1}$, Lexy Oktora Wilda ${ }^{1}$, Windi Hayuning Ristiani ${ }^{2}$ \\ ${ }^{1}$ Dosen Program Studi Pendidikan Ners Stikes Satria Bhakti Nganjuk \\ ${ }^{2}$ Mahasiswa Program Studi Pendidikan Ners Stikes Satria Bhakti Nganjuk \\ Email : Windihayuning88.wh@gmail.com
}

\begin{abstract}
Introduction : The high workload of nurses at Accident and Emergency Department can potentially be a stressor for nurses, giving rise to burnout, which is a collection of destructive physical, psychological and mental symptoms due to work fatigue. The general objective of this study was to determine the relationship of workload with the incidence of burnout of nurses in the Accident and Emergency Department of Nganjuk Hospital. Methods : The study design was a correlation with a cross sectional approach. The sampling technique used was total sampling technique, so that the sample size was 19 nurses. The independent variable was nurse workload and the dependent variable was nurse burnout. Data analyzed by Contingency Coefficient correlation test with $\alpha=0.05$. Results : The results showed that most of the 12 respondents $(63.2 \%)$ felt the workload as nurses in the Accident and Emergency Department was excessive. Mostly as many as 10 respondents (52.6\%) felt burnout in the medium category. There was a correlation between workload and the incidence of burnout of nurses at the Accident and Emergency Department of Nganjuk Hospital. It was evidenced from the results of the Contingency Coefficient test showing p-value $0.027 \leq \alpha(0.05)$, so Ha was accepted or H0 was rejected Conclusions : Therefore, it is recommended for the Nganjuk General Hospital to evaluate the planning of nurses' needs at the emergency department and conduct coping and self-efficacy training for nurses.
\end{abstract}

Keywords : Workload, Burnout, Nurse, Accident and Emergency Department.

\section{PENDAHULUAN}

Profesi perawat merupakan salah satu profesi yang penuh tekanan dan risiko, khususnya bagi perawat rumah sakit yang bertugas di Instalasi Gawat Darurat (IGD) yang dituntut mampu bertindak cepat dan tepat dalam memberikan pertolongan pada pasien yang berada dalam kondisi kegawatan. Beban kerja perawat di IGD yang sangat tinggi dapat berpotensi menjadi stresor bagi perawat. Stresor yang terjadi secara terus menerus dan tidak mampu diadaptasi oleh individu akan menimbulkan beberapa gejala yang disebut dengan burnout, yaitu kumpulan gejala fisik, psikologis dan mental yang bersifat destruktif akibat dari kelelahan kerja yang bersifat monoton dan menekan (Pangastiti, 2011). Individu yang mengalami burnout biasanya memiliki 
gejala psikosomatik (kelemahan dan insomnia), masalah emosional (cemas dan depresi), masalah sikap (permusuhan, apatis dan tidak percaya) dan masalah perilaku (agresivitas, lekas marah dan isolasi) (Ramdan, 2016). Berdasarkan studi pendahuluan dengan cara wawancara terhadap 6 perawat IGD RSUD Nganjuk pada tanggal 29-30 November 2018, seluruh perawat menyatakan hampir tidak memiliki waktu istirahat ketika bertugas, karena banyaknya pasien yang harus ditangani, sedangkan jumlah perawat terbatas. Seluruh perawat juga mengalami keluhan capek, sering mengantuk, sulit berkonsentrasi, kurang bersemangat dan mudah marah saat bekerja.

Berdasarkan data Kemenkes RI (2017), jumlah perawat di Indonesia pada tahun 2016 sebanyak 296.876 perawat dengan rasio 114,75 per 100.000 penduduk. Secara umum, jumlah rasio perawat di Indonesia masih jauh dari target tahun 2019 yaitu 180 per 100.000 penduduk. Pada tahun 2016, diketahui bahwa provinsi dengan rasio jumlah perawat tertinggi adalah DKI Jakarta yaitu sebesar 223,61 per 100.000 penduduk, sedangkan provinsi dengan rasio jumlah perawat terendah adalah Lampung yaitu sebesar 49,44 per 100.000 penduduk. Di Provinsi Jawa Timur, rasio jumlah perawat pada tahun 2016 sebesar 85,42 per 100.000 penduduk, jumlah tersebut lebih e-journal.stikessatriabhakti.ac.id rendah dari rasio jumlah perawat skala nasional. Berdasarkan data Dinas Kesehatan Kabupaten Nganjuk, jumlah perawat di Kabupaten Nganjuk pada tahun 2017 tercatat sebanyak 680 orang. Secara khusus di RSUD Nganjuk pada tahun 2017, jumlah perawat seluruhnya berjumlah 252 orang. Dari jumlah tersebut, perawat yang bertugas di IGD sebanyak 19 orang, sedangkan rata-rata jumlah kunjungan pasien IGD per bulan sekitar 1.800 pasien atau setara dengan 60 pasien per hari (24 jam). Artinya dalam kondisi antrian normal, satu orang perawat harus menangani tiga pasien IGD sekaligus.

Perawat merupakan salah satu komponen sumber daya manusia (SDM) rumah sakit yang terbanyak sekaligus merupakan ujung tombak pelayanan kesehatan rumah sakit, karena tugas dan fungsinya yang selalu bersentuhan langsung dengan pasien. Permasalahan yang dihadapi saat ini adalah kurangnya tenaga perawat di rumah sakit, sehingga meningkatkan beban kerja, memperpanjang jam kerja, dan meningkatkan stress kerja perawat (Chen, et.al., 2015). Meskipun perawat memiliki kedisiplinan dan ketekunan pada awal pekerjaan mereka, namun biasanya cenderung mengalami kelelahan dan berhenti bekerja setelah bekerja selama beberapa tahun karena menghadapi kesulitan tekanan pekerjaan yang tinggi. 
Beban kerja yang melebihi batas normal dapat menimbulkan burnout pada perawat yang ditandai dengan empat kondisi yaitu: (1) kelelahan fisik yang ditandai dengan mudah lelah, sakit kepala, mual, perubahan pola makan dan pola tidur serta merasa tenaganya terkuras berlebihan, (2) kelelahan emosi yang ditandai dengan depresi, frustrasi, merasa terperangkap di dalam pekerjaan, apatis, mudah marah, sedih dan tidak berdaya, (3) kelelahan mental atau sikap berupa prasangka negatif dan sikap sinis terhadap orang lain, (4) perasaan tidak mampu mencapai sesuatu yang berarti dalam hidup, ditandai oleh ketidakpuasan terhadap diri sendiri, pekerjaan, dan kehidupannya (Widiastuti dan Astuti, 2008). Kondisi tersebut jika dibiarkan dapat meningkatkan kesalahan dalam melakukan pekerjaan dan kecelakaan kerja, penurunan komitmen perawat terhadap profesinya, sehingga pada akhirnya berdampak pada tingginya turnover dan rendahnya mutu pelayanan keperawatan secara keseluruhan di rumah sakit (Yasmin, 2015).

Adapun tujuan dari penelitian ini Untuk mengetahui hubungan beban kerja dengan kejadian burnout perawat di Instalasi Gawat Darurat RSUD Nganjuk meliputi identifikasi beban kerja perawat di Instalasi Gawat Darurat RSUD Nganjuk, identifikasi kejadian burnout perawat di Instalasi Gawat Darurat RSUD
Nganjuk serta analisa hubungan beban kerja dengan kejadian burnout perawat di Instalasi Gawat Darurat RSUD Nganjuk.

\section{METODE PENELITIAN}

Metode penelitian yang digunakan adalah desain korelasi untuk mengetahui hubungan beban kerja dengan burnout perawat melalui pendekatan cross sectional.

Penelitian ini dilaksanakan pada tanggal $14-17$ Desember 2018 bertempat di Instalasi Gawat Darurat RSUD Nganjuk dengan menggunakan populasi seluruh petugas perawat yang bertugas di Instalasi Gawat Darurat Nganjuk sebanyak 19 pegawai. Teknik sampling penelitian adalah total sampling dengan menggunakan seluruh anggota populasi.

Pengumpulan data variable beban kerja perawat dan kejadian burnout dalam penelitian menggunakan kuisioner dengan skala Likert. Indicator beban kerja perawat meliputi pekerjaan memiliki tingkat resiko yang tinggi, mengerjakan dua atau lebih pekerjaan dalam waktu bersamaan, membutuhkan konsentrasi tinggi dalam menyelesaikan pekerjaan, pekerjaan yang tidak menentu datangnya, dan mendapat gangguan selama melakukan pekerjaan. Dalam proses analisa data dilakukan editing, coding, scoring, pengkategorian Burnout, uji korelasi Koefisien Kontingensi dengan $\alpha \quad 0,05$. Adapun 
pedoman untuk pengujian hipotesis adalah

bila $p$-value $\leq \alpha(0,05)$ maka Ha diterima atau $\mathrm{H} 0$ ditolak sedangkan bila $p$-value $>\alpha$

$(0,05)$ maka Ha ditolak H0 diterima.

\section{HASIL PENELITIAN}

1. Beban Kerja Perawat di Instansi Gawat Darurat RSUD Nganjuk

Tabel 1 Distribusi Frekuensi Berdasarkan Beban Kerja Perawat di Instalasi Gawat Darurat RSUD Nganjuk, Tanggal 14 - 17 Desember 2018.

\begin{tabular}{cccc}
\hline No & Beban Kerja Perawat & Frekuensi $(\boldsymbol{f})$ & Persentase (\%) \\
\hline 1. & Berlebih & 12 & 63,2 \\
2. & Tidak Berlebih & 7 & 36,8 \\
\hline & Jumlah & 19 & 100,0 \\
\hline
\end{tabular}

Berdasarkan tabel 1 menunjukkan bahwa dari 19 responden, sebagian besar yaitu 12 responden $(63,2 \%)$ merasakan beban kerjanya sebagai perawat di Instansi Gawat Darurat

2. Burnout Perawat di Instansi Gawat Darurat RSUD Nganjuk

Tabel 2 Distribusi Frekuensi Berdasarkan Burnout Perawat di Instalasi Gawat Darurat RSUD Nganjuk, Tanggal 14 - 17 Desember 2018.

\begin{tabular}{cccc}
\hline No & Burnout & Frekuensi $(\boldsymbol{f})$ & Persentase (\%) \\
\hline 1. & Tinggi & 0 & 0,0 \\
2. & Sedang & 10 & 52,6 \\
& Rendah & 9 & 47,4 \\
\hline & Jumlah & 115 & 100,0 \\
\hline
\end{tabular}

Berdasarkan tabel 2 menunjukkan bahwa dari 19 responden, sebagian besar yaitu 10 responden (52,6\%) merasakan burnout pada kategori sedang.

3. Hubungan Beban Kerja dengan Burnout Perawat di Instalasi Gawat Darurat RSUD Nganjuk

Tabel 3 Tabulasi Silang Beban Kerja dengan Burnout Perawat di Instalasi Gawat Darurat RSUD Nganjuk, Tanggal 14-17 Desember 2018..

\begin{tabular}{|c|c|c|c|c|c|c|c|c|}
\hline \multirow{3}{*}{ Beban Kerja } & \multicolumn{6}{|c|}{ Burnout Perawat } & \multirow{2}{*}{\multicolumn{2}{|c|}{ Jumlah }} \\
\hline & \multicolumn{2}{|c|}{ Tinggi } & \multicolumn{2}{|c|}{ Sedang } & \multicolumn{2}{|c|}{ Rendah } & & \\
\hline & $f$ & $\%$ & $f$ & $\%$ & $f$ & $\%$ & $\Sigma$ & $\%$ \\
\hline Berlebih & 0 & 0,0 & 8 & 42,1 & 4 & 21,1 & 12 & 63,2 \\
\hline Tidak berlebih & 0 & 0,0 & 1 & 5,3 & 6 & 31,6 & 7 & 36,8 \\
\hline
\end{tabular}




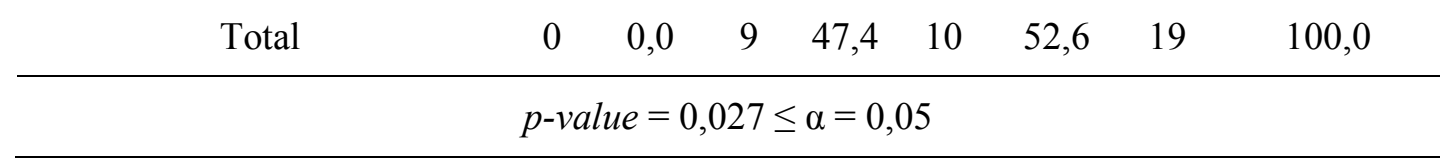

Berdasarkan tabel 4.3 diketahui bahwa dari 19 responden, hampir setengahnya mengatakan beban kerja yang dirasakannya berlebih dan burnout yang dialaminya berada pada kategori sedang, yaitu sebanyak 8 responden $(42,1 \%)$. Sedangkan sebaran data pada tabulasi silang secara umum menunjukkan pola hubungan yang searah, yaitu semakin berlebih beban kerja perawat, maka semakin tinggi tingkat burnout yang dialami, demikian pula sebaliknya, semakin normal atau tidak berlebih beban kerja perawat, maka semakin rendah tingkat burnout yang dialami.

Selanjutnya hasil uji Koefisien Kontingensi menunjukkan $p$-value $0,027 \leq \alpha(0,05)$, sehingga Ha diterima atau H0 ditolak, artinya ada hubungan beban kerja dengan kejadian burnout perawat di Instalasi Gawat Darurat RSUD Nganjuk.

Berdasarkan Analisa data umum responden menurut jenis kelamin responden diketahui bahwa dari 19 responden, sebagian besar berjenis kelamin laki-laki, yaitu 14 responden (73,7\%), berdasarkan umur responden diketahui bahwa dari 19 responden, sebagian besar memiliki usia 31-50 tahun, yaitu 14 responden $(73,7 \%)$, beradasarkan pendidikan terakhir responden diketahui bahwa dari 19 responden, hampir seluruhnya memiliki pendidikan D-3, yaitu 15 responden (78,9\%), dan berdasarkan lama kerja responden diketahui bahwa dari 19 responden, hampir seluruhnya telah bekerja selama lebih dari 5 tahun, yaitu 15 responden $(78,9 \%)$.

\section{PEMBAHASAN}

1. Beban Kerja Perawat di Instalasi Gawat Darurat RSUD Nganjuk

Berdasarkan hasil penelitian pada tabel 1 menunjukkan bahwa dari 19 responden, sebagian besar yaitu sebanyak 12 responden $(63,2 \%)$ merasakan beban kerjanya sebagai perawat di Instalasi Gawat Darurat berlebih. Fakta beban kerja perawat tersebut dapat dikaitkan dengan umur perawat, dimana sebagian besar memiliki usia 31-50 tahun, yaitu sebanyak 14 responden (73,7\%) dengan p-value sebesar 0,047 , sehingga ada hubungan yang signifikan antara umur dengan beban kerja perawat di Instalasi Gawat Darurat RSUD Nganjuk.

Menurut Manuaba (dalam Achyana, 2016), salah satu faktor internal yang dapat mempengaruhi 
persepsi beban kerja petugas kesehatan adalah faktor umur. Hasil penelitian Achyana mengkonfirmasi adanya hubungan yang signifikan antara umur sebagai faktor somatis dengan beban kerja karyawan. Sedangkan menurut Hasibuan (2009), karyawan dengan umur yang lebih muda umumnya memiliki fisik yang lebih kuat, daripada karyawan yang lebih tua. Karyawan dengan umur lebih tua cenderung lebih sensitif terhadap beban kerjanya, faktor tanggungan keluarga dan persoalan-persoalan rumah tangga membuat mereka mempersepsikan beban kerjanya menjadi lebih berat.

Berdasarkan uraian fakta dan teori di atas, maka peneliti dapat mengajukan opini bahwa sebagian besar responden perawat IGD dalam penelitian ini memiliki umur 31-50 tahun, dimana pada umur tersebut seseorang umumnya sudah berumah tangga dan memiliki anak-anak maupun tanggungan keluarga yang lain. Dalam kondisi tersebut, maka seseorang cenderung memiliki beban hidup yang lebih berat, disamping ia harus melaksanakan pekerjaannya sebagai perawat, ia juga dihadapkan pada berbagai persoalan hidup yang harus ditanggungnya. Ditambah lagi semakin bertambahnya umur, kekuatan fisik perawat semakin menurun, sehingga mudah lelah dan semakin sensitif merasakan beban pekerjaannya terasa semakin berat untuk dilakukan.

2. Burnout Perawat di Instalasi Gawat Darurat RSUD Nganjuk

Berdasarkan hasil penelitian pada tabel 2 menunjukkan bahwa dari 19 responden, sebagian besar yaitu sebanyak 10 responden (52,6\%) merasakan burnout pada kategori sedang. Fakta burnout perawat tersebut dapat dikaitkan dengan pendidikan terakhir perawat, hampir seluruh responden memiliki pendidikan D-3, yaitu sebanyak 15 responden $(78,9 \%)$ dengan $p$-value sebesar 0,033, sehingga ada hubungan yang signifikan antara pendidikan dengan burnout perawat di Instalasi Gawat Darurat RSUD Nganjuk.

Schaufeli \& Buunk (dalam Tawale, dkk, 2011) menyatakan bahwa burnout dapat dipengaruhi oleh faktor demografis, termasuk di dalamnya adalah tingkat pendidikan karyawan. Notoatmodjo (2011) menjelaskan bahwa pendidikan memiliki peranan yang besar dalam 
membentuk pengetahuan seseorang tentang kesehatan. Semakin tinggi tingkat pendidikan seseorang, maka semakin mudah orang tersebut dalam menerima informasi, sehingga semakin banyak pula pengetahuan yang dimiliki. Dalam konteks burnout perawat, maka perawat yang memiliki pendidikan lebih tinggi cenderung memiliki kemampuan koping dan efikasi diri yang lebih baik, sehingga dapat mengatasi burnout yang dialami dan tetap dapat mempertahankan kinerja serta loyalitasnya terhadap organisasi rumah sakit.

Berdasarkan uraian fakta dan teori di atas, maka peneliti dapat mengajukan opini bahwa hampir seluruh responden memiliki pendidikan terakhir D-3, dimana tingkat pendidikan ini sudah cukup tinggi, namun masih belum memadai untuk dapat memiliki pengetahuan tentang koping dan efikasi diri ketika menghadapi burnout. Karena perawat kadangkala masih mengalami stres, putus asa, dan merasa hidup kurang berarti dan sebagian gejala burnout lainnya dalam kategori sedang. Sedangkan perawat yang memiliki tingkat pendidikan S-1 dalam penelitian ini diketahui seluruhnya memiliki tingkat burnout yang rendah. Hal ini dikarenakan perawat sudah memiliki cukup pengetahuan tentang koping dan efikasi diri untuk dapat mengatasi burnout yang dirasakannya.

3. Hubungan Beban Kerja dengan Burnout Perawat di Instalasi Gawat Darurat RSUD Nganjuk

Berdasarkan hasil penelitian tabel 3 bahwa dari 19 responden, hampir setengahnya mengatakan beban kerja yang dirasakannya berlebih dan burnout yang dialaminya berada pada kategori sedang, yaitu sebanyak 8 responden (42,1\%). Sedangkan sebaran data pada tabulasi silang secara umum menunjukkan pola hubungan yang searah, yaitu semakin berlebih beban kerja perawat, maka semakin tinggi tingkat burnout yang dialami, demikian pula sebaliknya, semakin normal atau tidak berlebih beban kerja perawat, maka semakin rendah tingkat burnout yang dialami. Selanjutnya hasil uji Koefisien Kontingensi menunjukkan p-value $0,027 \leq \alpha(0,05)$, sehingga $\mathrm{Ha}$ diterima atau H0 ditolak, artinya ada hubungan beban kerja dengan 
kejadian burnout perawat di Instalasi Gawat Darurat RSUD Nganjuk.

Menurut Widiastuti dan Astuti (2008), beban kerja yang melebihi batas normal dapat menimbulkan burnout pada perawat yang ditandai dengan empat kondisi yaitu: kelelahan fisik, kelelahan emosi, kelelahan mental, dan perasaan tidak mampu mencapai sesuatu yang berarti dalam hidup. Pangastiti (2011) menguraikan tentang beban kerja perawat di IGD yang sangat tinggi dapat berpotensi menjadi stresor bagi perawat. Stresor yang terjadi secara terus menerus dan tidak mampu diadaptasi oleh individu akan menimbulkan beberapa gejala yang disebut dengan burnout, yaitu kumpulan gejala fisik, psikologis dan mental yang bersifat destruktif akibat dari kelelahan kerja yang bersifat monoton dan menekan. Yasmin (2015) menambahkan bahwa jika kondisi burnout tersebut dibiarkan dapat meningkatkan kesalahan dalam melakukan pekerjaan dan kecelakaan kerja, penurunan komitmen perawat terhadap profesinya, sehingga pada akhirnya berdampak pada tingginya turnover dan rendahnya mutu pelayanan keperawatan secara keseluruhan di rumah sakit.

Berdasarkan uraian fakta dan teori di atas, maka peneliti dapat mengajukan opini bahwa hasil penelitian ini telah berhasil membuktikan adanya hubungan yang signifikan antara beban kerja perawat dengan burnout perawat di IGD RSUD Nganjuk. Dalam penelitian ini ditemukan bahwa sebagian besar perawat merasakan beban kerja yang berlebihan, namun tidak mampu mengatasi keadaan tersebut dengan baik, sehingga mereka mengalami gejala-gejala burnout atau kelelahan kerja, baik secara fisik maupun mental. Dalam kondisi tersebut, perawat di IGD RSUD Nganjuk memerlukan penyegaran agar gejala burnout tidak semakin berlarut-larut, sehingga berdampak pada penurunan kinerja. Menurut Retno (2013), rumah sakit perlu memberikan pelatihan kepada perawat tentang strategi koping dan efikasi diri. Selain itu, perlu diupayakan lingkungan kerja yang lebih kondusif dan memberlakukan sistem rotasi perawat secara lebih sistematis dan terukur.

\section{KESIMPULAN}


Hasil Penelitian menunjukkan sebagian besar yaitu 12 responden $(63,2 \%)$ merasakan beban kerjanya sebagai perawat di Instalasi Gawat Darurat berlebih serta sebagian besar yaitu 10 responden $(52,6 \%)$ merasakan burnout pada kategori sedang. Adanya hubungan beban kerja dengan kejadian burnout perawat di Instalasi Gawat Darurat RSUD Nganjuk. Hal ini dibuktikan dari hasil tabulasi silang yang menunjukkan pola hubungan yang searah, yaitu semakin berlebih beban kerja perawat, maka semakin tinggi tingkat burnout yang dialami, demikian pula sebaliknya, semakin normal atau tidak berlebih beban kerja perawat, maka semakin rendah tingkat burnout yang dialami. Hasil uji Koefisien Kontingensi menunjukkan $p$-value $0,027 \leq \alpha(0,05)$, sehingga Ha diterima atau $\mathrm{H} 0$ ditolak.

Saran dalam penelitian ini diantaranya melakukan deteksi diri tentang gejala burnout yang dialaminya. Selanjutnya perawat dapat berkonsultasi dengan psikiater untuk memantau kondisi kejiwaan dan meminta saran agar dapat mengembangkan koping dan efikasi diri. Perlunya juga untuk selalu mendekatkan diri dengan Tuhan dan doa dan ibadah, sehingga dapat menjadi sumber kekuatan spiritual bagi perawat, melakukan evaluasi perencanaan kebutuhan tenaga perawat di IGD dan menyelenggarakan pelatihan koping dan efikasi diri bagi perawat IGD agar mampu mengatasi stresor yang dialaminya. Rumah sakit juga perlu mengupayakan penciptaan lingkungan kerja di IGD yang lebih kondusif dan nyaman, sehingga dapat meminimalisir kelelahan kerja, mengembangkan hasil penelitian ini dengan mengambil variabel penelitian yang berhubungan dengan burnout perawat, misalnya meneliti tentang keterampilan koping perawat di IGD.

\section{DAFTAR PUSTAKA}

Achyana, M. 2016. Faktor-Faktor yang Mempengaruhi Beban Kerja Room Attendant di Grand Jatra Hotel Pekanbaru. Jom FISIP Vol.3 No.2Oktober 2016. Jom FISIP Vol.3 No. 2Oktober 2016. Hal. 1-12.

Chen, S. Y., et.al. 2015. Organizational Justice, Trust, And Identification and Their Effects On Organizational Commitment in Hospital Nursing Staff. BMC Health Services Research (2015) 15:363.

Hasibuan, Malayu S.P. 2009. Manajemen: Dasar, Pengertian, dan Masalah. Edisi Revisi. Jakarta: Bumi Aksara.

Kemenkes RI. 2017. Profil Kesehatan Indonesia 2016. Kemenkes RI.

Notoatmodjo, S. 2010. Metodologi Penelitian Kesehatan. Jakarta: Rineka Cipta.

Pangastiti, N. K. 2011. Analisis Pengaruh Dukungan Sosial Keluarga terhadap Burnout pada Perawat Kesehatan di Rumah 
Sakit Jiwa. Skripsi. Semarang: Fakultas Ekonomi Universitas Diponegoro.

Ramdan, I. 2016. Analisis Faktor yang Berhubungan dengan Burnout pada Perawat Kesehatan Jiwa. Jurnal Fakultas Kesehatan Masyarakat Universitas Mulawarman. Volume 4 Nomor 2 Agustus 2016.

Tawale, E.; Widjajaning, B.; Nurcholis G. 2011. Hubungan antara Motivasi Kerja Perawat dengan Kecenderungan Mengalami Burnout pada Perawat di RSUD-Serui Papua. Surabaya: Fakultas Psikologi Universitas HangTuah Surabaya.
Widiastuti, Dhian Zusmiasih dan Kamsih Astuti. 2008. Hubungan Antara Kepribadian Hardiness dengan Burnout pada Guru Sekolah Dasar. Naskah Publikasi. Yogyakarta: Fakultas Psikologi Universitas Marcu Buana.

Yasmin, A. 2015. Analisis Pelaksanaan Pelayanan Kesehatan Pada Era Jaminan Kesehatan Nasional (JKN) di Puskesmas Andalas Kota Padang tahun 2015. Padang: Fakultas Kesehatan Masyarakat Universitas Andalas. 